\title{
Attention to emotional stimuli in borderline personality disorder - a review of the influence of dissociation, self-reference, and psychotherapeutic interventions
}

\author{
Dorina Winter(D
}

\begin{abstract}
Interactions between attention and processing of emotional stimuli shed light on both sensitivity to emotional stimuli as well as emotion dysregulation. Both of the latter processes have been proposed as central characteristics of altered emotion processing in those with borderline personality disorder (BPD). This review first summarizes the conflicting behavioural, psychophysiological and neuroimaging evidence for the hypothesis that emotional dysregulation should be reflected by higher distractibility through emotional stimuli in those with BPD. Dissociation, self-reference, as well as symptom severity modulated by psychotherapeutic interventions are proposed to help clarify divergent findings. Data suggest an association of dissociation with impaired task continuation during the presentation of interfering emotional and neutral stimuli, as well as high recruitment of neuronal attention networks together with a blunted emotional response. Considering self-reference, evidence suggests that negative rather than positive information may be more self-relevant to those with BPD. This may be due to a negative self-concept and self-evaluation. Social or trauma-relevant information attracts more attention from individuals with BPD and thus suggests higher self-relevance. After psychotherapeutic interventions, initial evidence may indicate normalization of the way attention and emotional stimuli interact in BPD. When studying attention-emotion interactions in BPD, methodological heterogeneities regarding sample, task, and stimulus characteristics need to be considered. When doing so, dissociation, self-reference, and psychotherapeutic interventions offer promising targets for future studies on attention-emotion interactions in those with BPD. This could promote a deeper insight into the affected individuals' struggle with emotions.
\end{abstract}

Keywords: Borderline personality disorder, Emotion regulation, Cognition-emotion interaction, Psychotherapy, Functional magnetic resonance imaging

\section{Background}

Emotional dysregulation constitutes the central characteristic of borderline personality disorder (BPD [1-3]). This is reflected in all three BPD core pathology domains: affective dysregulation, interpersonal disturbances and behavioural dysregulation $[4,5]$. Indeed, the ability to control emotional reactions has been identified as an important capability to maintain mental health for everyone [6-8]. One can use mental capabilities to modulate emotional reactions in different ways. For

Correspondence: Dorina.Winter@zi-mannheim.de

Department of Psychosomatic Medicine and Psychotherapy, Central Institute of Mental Health, Medical Faculty Mannheim/Heidelberg University, PO Box 12212068072 Mannheim, Germany example, one's attentional focus quite efficiently modulates the processing of emotional stimuli, including emotional responses-but this is also the case vice versa (for reviews see [9-13]). These mutually influencing processes will further be called attention-emotion interactions. Attention constitutes a filter favouring e.g. emotional information, which is then preferentially stored in long-term memory and consequently influences subsequent cognitive processes and behaviours congruently (see Fig. 1) [14]. Thus, attention-emotion interactions offer information on the way a person processes emotional stimuli: First, they indicate emotional sensitivity, which describes how easily a person reacts to emotional information. Even in healthy populations, 


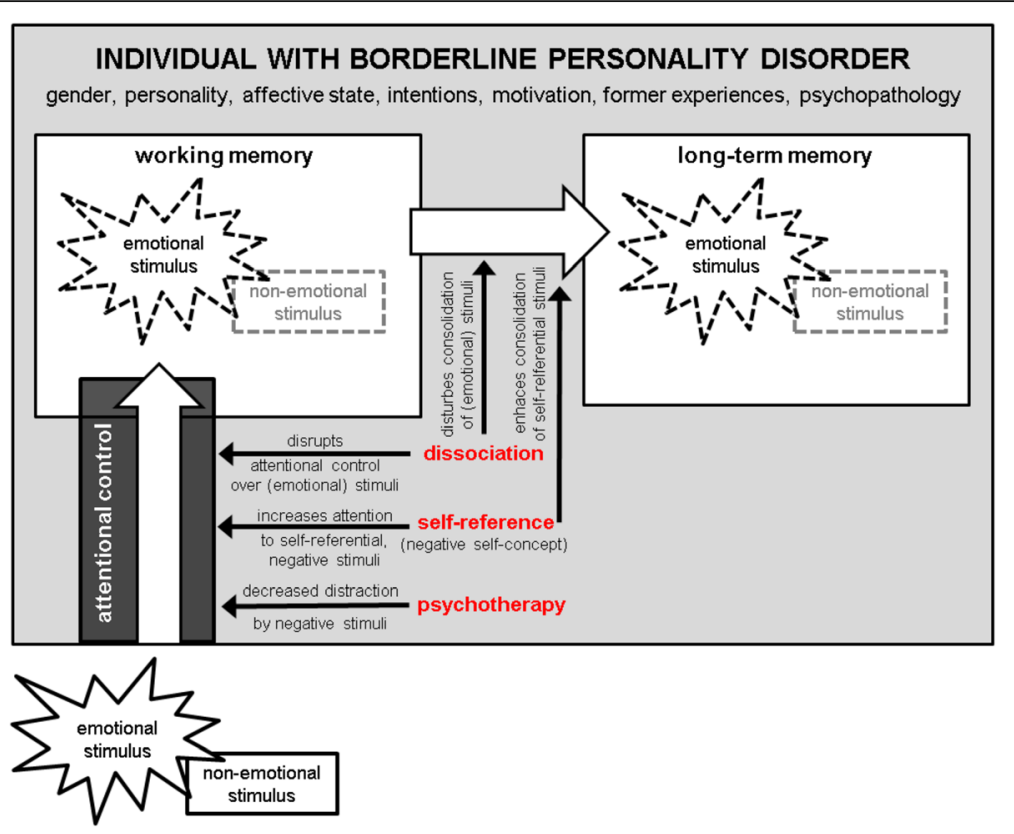

Fig. 1 Schematic summary of the proposed influence of dissociation, self-reference and psychotherapeutic interventions on attention and memory during the processing of emotional stimuli. This figure summarizes how dissociation, self-reference and symptom severity may modulate the processing of emotional information in individuals with borderline personality disorder, starting from attention to the stimulus, encoding into working memory, storage into long-term memory and thus, again, modulating the attentional focus selected. Figure adapted from Winter et al., [195]

emotional information attracts more attention compared to less emotional information [9, 10, 15]. Sensitivity to emotional stimuli prepares and facilities selective reactions to potentially relevant environmental cues while inhibiting concurrent-and potentially distracting-stimuli and actions [16, 17]. However, this mechanism can become disadvantageous, when emotional stimuli disrupt the processing of target stimuli and goal-directed behaviours [18-23]. Second, the ability to direct attentional focus to or away from a stimulus is a common emotion regulation strategy, called "distraction" [24]. In certain tasks in which regulating reactions to emotional stimuli is not intentional, it also has been considered an implicit emotion regulation strategy [25]. In general, shifting attention away from an emotional stimulus is an effective and comparatively fast strategy [26, 27] to reduce negative affect [27-33] and negative cognitions [34], particularly when stimuli are highly arousing [35].

Brain imaging studies (for reviews see [9-11]) indicated that attention-emotion interactions involve brain regions associated with the active maintenance of goalrelevant information in working memory, for example the dorsolateral prefrontal cortex (dIPFC) and the lateral parietal cortices [36-39]. Also, higher activity in brain regions indicating emotion processing, including the amygdala, the medial prefrontal cortex, and the ventrolateral prefrontal cortex (vlPFC) was found [40-44]. In addition, higher activity in occipital and occipitotemporal brain regions during attention-emotion interactions [45-48] suggests sensory amplification [10]. The anterior cingulate cortex (ACC) has often been associated with attention-emotion interactions, but its role is inconsistent [49-53]. One distinction is between the dorsal ACC/midcingulate cortex, which may rather indicate cognitive conflict, and the rostral/perigenual and subgenual ACC, which may rather indicate emotional conflict [54-57]. More particularly, successful attentional control when processing emotional stimuli has been associated with higher activity in the inferior frontal gyrus (IFG)/vlPFC [58, 59]. On the contrary, higher emotional conflict has been associated with higher ACC and dlPFC activity [50-53, 55, 56, 60, 61].

Not surprisingly, studies examining emotion processing (predominantly viewing emotional and neutral pictures) in BPD reveal more or less the described neural networks to be disrupted in comparison to healthy control participants (for reviews see [62-64]). But what about tasks directly targeting attention-emotion interactions?

\section{Attention-emotion interactions in BPD-current evidence}

Studying attention-emotion interactions has been of strong interest, particularly to gain insight into emotional sensitivity in those with BPD. While individuals with BPD report particularly long and intense emotional reactions [65-68], behavioural measures of attentionemotion interactions do not provide clear evidence. Paradigms examining emotional sensitivity mainly require 
participants to perform a task, e.g. letter memorizing or colour naming, during the presentation of interfering emotional content of words or photographical pictures. If reaction times are longer, more mistakes or better memory is exhibited for emotional compared to control stimuli, they are assumed to attract more attention. Previous studies partially revealed longer reaction times and/or less accuracy during the presentation of negative [69-74] and positive [70] in contrast to neutral content in those with BPD compared to healthy controls. However, a substantial number of studies have not found any group differences [75-78]. Overall, apparently, more intense stimuli [79] with personal relevance [69-71] are more likely to provide behavioural evidence for higher attention to distracting emotional stimuli in those with BPD.

Functional neuroimaging studies found that, in comparison to healthy controls, individuals with BPD showed higher activity in areas indicating stronger emotional processing, such as the amygdala $[79,80]$ and insula [79] for negative pictures in comparison to a control condition. Also, higher medial prefrontal cortex activity has been observed in BPD for task interfering positive compared to neutral stimulus content [81]. When word stimuli were used as distractors, activity was elevated in the superior temporal gyrus-a brain region associated with semantic processing [81]. In the subgenual and perigenual parts of the ACC and adjacent brain areas, the difference between negative and neutral distracting stimuli was smaller in the BPD group than in the healthy control group $[78,82,83]$. In the dorsal ACC, similarly, some studies found a smaller activity difference for negative compared to neutral stimuli, while one study reported higher activity for positive vs. neutral stimuli in BPD [78, 81, 83]. Additionally, individuals with BPD show stronger coupling between the amygdala as well as the dACC with brain regions indicating (among other) increased stimulus saliency (medial prefrontal cortex/hippocampus for the amygdala or medial prefrontal cortex/insula/posterior cingulate/frontoparietal cortices for the $\mathrm{dACC}$ ), during the processing of aversive distractors [84]. Taken together, referring to the role of these noted brain areas in attention-emotion interactions [9-11], these data suggest that task-irrelevant emotional information has particular salience for individuals with BPD. Concurrently, findings on a smaller ACC activity difference as response to negative compared to neutral stimuli could also indicate a smaller difference in the emotional conflict elicited by negative compared to neutral stimuli. This finding is supported by previous evidence suggesting more negative evaluations of information previously rated as neutral by healthy control samples $[85,86]$.

In summary, evidence suggests that individuals with BPD tend to show an enhanced distractibility by emotional content than healthy controls and stronger processing of the distracting emotional stimuli, suggesting higher sensitivity to emotional stimuli. However, evidence is somewhat heterogeneous on the behavioural level as well as with respect to the involvement of specific brain regions. This heterogeneity may be due to methodological differences such as sample or task characteristics $([71,75,76]$; see also below "Consideration of Methodological Heterogeneities"). Also psychological mechanisms have been suggested to further modulate attention-emotion interactions in those with BPD [69-71, 75, 76, 79, 81, 84, 87-90]. Three important, but understudied, processes are: dissociation $[79,81$, 84, 88-90], self-reference of stimulus content [69-71], and psychotherapeutic interventions [87].

\section{Dissociation}

Dissociation is defined as the "disruption of and/or discontinuity in the normal integration of consciousness, memory, identity, emotion, perception, body representation, motor control, and behavior" [91, 92]. As such, dissociation is a subjective experience, which is usually assessed via self-reported symptom intensities. The vast majority of individuals with BPD experiences transient dissociative symptoms [93], particularly when stress levels are high $[68,93,94]$. Even though it is a salient phenomenon in BPD, the influence of dissociation on attention-emotion interactions is not well understood. Individuals with BPD experiencing recurrent dissociation showed broad deficits in neuropsychological behavioural and psychophysiological measures, including attention, executive functioning, working memory, long-term memory, and general cognitive abilities, while BPD patients who rarely experience dissociation only showed deficits in executive functioning [88]. High levels of current dissociation were also associated with an impaired ability to maintain task-related performance when facing distracting information [81]. With respect to general processing of negative stimuli, individuals with BPD reported lower pain sensitivity $[95,96]$ and worse aversive conditioning $[97,98]$ during high levels of dissociation. Furthermore, high levels of dissociation mediated startle responses and skin conductance in response to negative pictures [89]. Although not always addressing attention-emotion interactions themselves, these studies would suggest impaired attentional control on the one hand, as well as diminished sensitivity to emotional stimuli on the other hand when levels of dissociation are high in BPD.

With respect to brain activity correlates, higher dissociation levels in those with BPD were associated with lower amygdala activity in response to repeatedly presented negative pictures [99]. More specific to attentionemotion interactions, high dissociation levels in those 
with BPD correlated with reduced amygdala (and hippocampal) activation [79]. In addition, a stronger coupling between the amygdala and the ACC was found in BPD individuals with high levels of dissociation during the presentation of distracting negative stimuli [84]. Induced dissociation during a colour-naming task was also associated with higher IFG activity during distracting negative compared to neutral stimuli [81]. These findings support current models of dissociation in post-traumatic stress disorder (PTSD) $[100,101]$ and depersonalization disorder [102], highlighting their trans-diagnostic relevance. Both models hypothesize blunted reactivity to negative stimuli in areas associated with emotion processing (i.e., amygdala), as well as higher activity in areas associated with processing emotional conflict and emotion regulation (ACC, medial and dIPFC) in these patient groups during the processing of emotional stimuli. Such a brain pattern was previously summarized as "emotional overmodulation" [100, 101], which fits well with the above-mentioned behavioural and psychophysiological evidence. Potential emotional reactions may be excessively regulated, leading to reduced emotional responses. Unfortunately, the reported study designs do not allow answering the question whether of a "normalization" of brain activity occurring in BPD during dissociation can be observed in comparison to healthy participants e.g. in limbic brain regions. However, it does suggests that additional aberrant activity within-and connectivity to-brain regions associated with emotion regulation could be expected during dissociation in those with BPD. This would oppose the idea of an overall normalization of neural activity during dissociation.

In summary, few studies examined the direct modulation of attention-emotion interactions by dissociation in those with BPD [79, 81, 84]. However, the overall evidence supports two main findings for those with BPD: 1) maintaining attention to a target task during the presentation of interfering emotional and neutral information is impaired during dissociation, and 2) attention-emotion interactions during dissociative states may be characterized by high recruitment of attentional (and emotion regulation) resources associated with a blunted emotional response. This suggests dysfunctional allocation of attentional resources during attention-emotion interactions, namely for emotion regulation rather than task performance. Future studies need to clarify further the role of dissociation as trait $[88,99]$ versus state $[79,81,84,89,95-98]$, as it appears that this distinction may be relevant [81].

\section{Self-reference}

It has been argued that emotional cues are processed preferentially as they may contain information relevant to oneself, allowing goal-directed behaviours [16, 17].
This notion is supported by the fact that a person's personality traits, state, as well as intention, motivation and decision making processes are known to influence attention-emotion interactions, in terms of so-called "top-down modulations" [103-106]. However, in favour of experimental control, most studies use standardized emotional stimuli, such as words and/or pictures. Nevertheless, this neglects the extent to which this information may refer to the individual participants. For example, participants with BPD evaluated positive or neutral words more negatively than healthy participants when these were presented with reference to themselves rather than with reference to another person [85]. In studies already mentioned on attention-emotion interactions in BPD, emotional stimuli attracted particular attention when the stimuli were selected individually [71] or when referring to BPD-related issues [69, 70].

Although several studies suggest alterations in neural networks associated with self-referential processing in a resting state or during self-referential processing [90, 107-109], evidence on the role of self-reference for attention-emotion interactions in BPD is sparse. In one case, an intensifying role of self-relevance on activity differences between a group with BPD and healthy participants e.g. in the IFG and the rostral ACC can be inferred [78]. One EEG study using a self-referential encoding task also reported a more intensive response to negative compared to positive traits in an event-related potential which has been associated with enhanced stimulus salience, in youth with BPD, in comparison to healthy participants [110]. However, both studies lack direct comparison between self- vs. non-self-referential (emotional) information, limiting conclusions regarding the role of self-reference on attention-emotion interactions in individuals with BPD.

If self-reference matters, which type of stimulus content may elicit particularly strong self-reference in those with BPD? As demonstrated through the preferential processing of positive, self-related stimuli in the general population [111-115], a person's self-concept appears to be highly relevant. Individuals with BPD report low selfesteem $[116,117]$ and provide negative self-descriptions [118]. They show high levels of self-criticism and feelings of inferiority [119] and are more shame-prone [120]. They also consider their body as particularly aversive [121, 122]. In light of this evidence and supported by a study in youth with BPD [110], negative stimuli likely provide more self-reference and positive stimuli provide less self-reference in those with BPD, thus, differentially affecting attention-emotion interactions and probably its neural correlates.

Additionally, self-descriptions and attitudes towards themselves are at least somehow unstable in those with BPD [92, 107, 123, 124]. This is in line with the 
experience of a poor sense of self, which constitutes a diagnostic criterion of BPD [92]. Accordingly, it is reasonable to assume that there could be certain instabilities in the way one refers to stimuli to oneself $[125,126]$. However, such instabilities have not yet been addressed with respect to attention-emotion interactions.

Finally, stimuli used to study attention-emotion interactions also involve events, photographic scenes, and/or faces. Due to the interpersonal difficulties frequently experienced by individuals with BPD, social information may be of reasonably higher self-relevance and thus attract more attention, as supported by a recent study [74]. In line with this, a trend to higher attention to selfin comparison to other-referential, social information has been suggested by a social memory paradigm [86] Further, a majority of individuals with BPD report significant, repetitive aversive childhood experiences [127-129] and PTSD is also frequently diagnosed in those with BPD (17-39.2 \%; [130-132]). Thus, traumarelated stimuli may attract more attention in BPD than in healthy controls.

In summary, individuals with BPD show a marked negative self-concept and low self-esteem, which may be unstable. Social or trauma-relevant information may provide particular self-reference for those with BPD. Thus, negative, social, or trauma-relevant information may lead to stronger attention-emotion interactions in those with BPD than in control groups, namely by capturing more attention as well as additional recruitment of neural networks involved in self-referential processing (e.g. cortical midline structures [133]).

\section{Psychotherapeutic interventions and symptom severity}

Psychotherapeutic interventions suggest medium effect sizes with respect to symptom reduction in BPD [134-136] but related alterations in attention-emotion interactions have been seldom examined $[87,137,138]$. Such changes could be indicators of both improved emotional sensitivity as well as emotion regulation.

On the behavioural level, there is one study reporting prolonged reaction times to BPD-relevant stimulus content normalized in those who recovered from BPD after 3 years of outpatient psychotherapy [87]. Neuroimaging studies, however, did not find significant behavioural alterations post therapy $[137,138]$.

Which changes in neural correlates of attentionemotion interactions can be expected after psychotherapy? Reviews have suggested that altered brain patterns normalized after psychotherapy in other mental illnesses such as obsessive-compulsive disorder, depression, and schizophrenia [139-141]. However, there may be an increased level of activity in additional brain areas after psychotherapy, as observed in panic disorder and PTSD
[140-142], which may indicate a 'compensatory' brain response obtained to cope with challenging stimuli and responses. Studies focusing on neural correlates of emotion processing in BPD patients found that activity of brain regions associated with emotion processing (i.e., the amygdala) declined after successful psychotherapy targeting emotion regulation [143-145]. With respect to attention-emotion interactions, a pre-post design study also showed increased dorsal prefrontal (dorsal ACC, dIPFC, frontopolar cortex) and decreased vlPFC and hippocampal activity, while BPD participants viewed distracting negative stimuli from before to after transference-focused psychotherapy [138]. This suggests increased response in brain areas that control attention to (emotional) stimuli and decreased response in brain regions associated with emotional response. However, due to the lack of a respective control group in this study, it is not possible to conclude whether this represents a normalization of brain activity patterns. A study by our research group found decreased activity over time in the inferior parietal lobe/supramarginal gyrus during distraction from negative rather than neutral stimuli in those with BPD from before to after dialectical behaviour therapy (DBT), which was correlated with improvements in self-reported borderline symptom severity [137]. Thus, in future studies, both a normalization of fronto-parietal-limbic activity as well as additional recruitment of frontal areas involved in the executive system could be expected in response to distracting emotional stimuli following symptom improvement in BPD after psychotherapy.

Overall, evidence for alterations of alterations of attention-emotion interactions after psychotherapy in BPD is still very preliminary and offers many future research directions. Over the last few decades, several psychotherapeutic approaches have been developed or adapted specifically to treat individuals with BPD [135]. However, only DBT and transference-focused psychotherapy explicitly studied attention-emotion interactions in those with BPD [137, 138]. Here, specific psychotherapies may go in hand with specific alterations in attention-emotion interactions. For example, DBT, which focuses on emotion regulation [146], may be associated with a decrease in sensitivity to emotional stimuli and an increased ability to regulate emotional responses. In contrast, schema-focused therapy [147], which focuses on strong emotional reaction to selfrelevant triggers, may be associated with normalized sensitivity to self-relevant emotional triggers and thus, less effort to control attention over triggers. It would be optimal if future randomized controlled trials included paradigms to measure different types of attentionemotion interactions and their neural correlates, in order to gain knowledge regarding intervention-specific alterations in BPD. 
In addition to psychotherapy, future research on attention-emotion interactions could also examine nonpsychotherapeutic interventions for those with BPD. For example, specific neural targets such as the amygdala, insula, ACC, IFG/vlPFC or dlPFC can be trained in those with BPD using functional magnetic resonance imaging (fMRI) feedback - referred to as real-time fMRI neuro-feedback [148-151] - allowing for attentionemotion interactions and their neural correlates to be modulated. Brain stimulating techniques (e.g., transcranial magnetic stimulation or transcranial direct current stimulation) may be of interest, as they are known to modulate attention-emotion interactions [152-154]. Additionally, pharmacological interventions, which target the oxytocin system $[155,156]$ or hypothalamic-pituitary-adrenal axis functioning [157], have revealed enhanced attentional control of/reduced interference by negative stimuli in those with BPD. Finally, antidepressants may also alter attention-emotion interactions in BPD patients [158-160].

In summary, even though initial evidence suggests normalization of attention-emotion interactions following psychotherapeutic interventions, future research needs to add to this evidence and to clarify the role of specific interventions regarding these processes.

\section{Consideration of methodological heterogeneities}

Per se, BPD is a very heterogeneous mental condition, with five out of nine criteria to be met to obtain the diagnosis [92]. In extreme cases, two individuals with BPD may fulfil only one joint BPD criterion. To account for this, it may be relevant to either select or - even better - compare individuals with BPD who show certain symptoms of interest (e.g. $[81,137])$ or to link results to symptom domains (e.g. [79, 138]). Apart from these BPD eminent heterogeneities, the reported studies show methodological heterogeneities in sample and task characteristics, which need to be considered when interpreting their findings.

With respect to sample characteristics, the role of comorbid disorders in the BPD samples needs further exploration. Evidence suggests that PTSD, dissociative disorders, major depression and attention deficit hyperactivity disorder may influence emotion processing and attention-emotion interactions in those with BPD [71, 161-165].

In addition, individual arousal, mood, or emotional state has been shown to influence attention-emotion interactions state-congruently [166-168]. As individuals with BPD experience more intense and prolonged emotional states compared to healthy controls [65-68], it is likely that their emotional states influence attentionemotion interactions more differentially than observed in healthy controls.

Further, findings cannot be generalized across gender, as many studies predominantly included women (except [80]). This is relevant, as gender influences emotion processing and regulation [169-171]. In $\mathrm{BPD}$ research, further gender differences can be expected, as men often show lower overall symptomatology compared to women $[172,173]$ and differ in their comorbidity profile (i.e., males: more often antisocial personality disorder; women: more often PTSD and eating disorders [131, 172-175]). Also, serotonergic functions, which have been associated with emotion processing and impulsivity, appear to differ between genders in those with BPD [176178]. Thus, it is reasonable to study male and female individuals with BPD separately, but also comparatively.

When interpreting results, it is necessary to consider that many studies did not exclude the use of psychotropic medication, even though they are known to alter emotion processing and its neural correlates [62, 179-182]. It has been proposed to include medication load as a covariate in analyses, if the statistical design and the variance in medication provides enough power to do so [64]. Future research may also examine the influence of different types of medication on attention-emotion interactions in BPD.

In summary, several sample characteristics such as comorbidities, emotional state, medication and gender may influence a study's results and therefore may be of interest for its interpretation. Often, due to comparatively small sample sizes and thus, power challenges, analyses addressing these issues are omitted or cannot be conducted to a considerable degree. Thus, examining the role of these variables on attention-emotion interactions in BPD need to be subject to future research.

With respect to task characteristics, it needs to be stressed that this review aggregated findings across different task types, as the amount of available studies was mainly limited. The tasks used in the reported studies have been discussed to examine specific mental processes, such as response inhibition and impulse control (for further information see $[161,183]$ ). These tasks also differed in their difficulty level, e.g. through (slower or faster) timing or (lower or higher) cognitive load. In the general population, if the task has low to moderate difficulty, higher difficulty is associated with stronger attention-emotion interactions as evinced by prolonged reactions in the presence of distracting emotional compared to neutral stimuli [184-186]. However, if task difficulty is very high (e.g. as evinced by many mistakes made), this effect is not present anymore [10, 187-189]. With respect to $\mathrm{BPD}$, this would suggest that altered attention-emotion interactions may be observed most likely at moderate to difficult tasks (e.g. emotional working memory task [79]), while no or smaller effects may be observed when with easy or very difficult tasks (e.g. emotional Stroop task $[78,81])$. 
Furthermore, stimulus characteristics need to be considered, as stimulus types such as faces and scenes are associated with stronger differences in task performance during the presentation of emotional compared to neutral stimuli than words $[9,190]$. In addition, studies often include stimuli that are exclusively of negative or rather neutral valence. Positive items have rarely been used [70, 85], limiting this review of attention-emotion interactions mainly to negative stimuli. Particularly for BPD, it is often debated whether neutral items are actually neutral or rather negatively biased [63, 64, 191], questioning the usual procedure to contrast emotional stimuli with neutral stimuli [69-73, 75-78, 81]. However, it is under debate as to which would be the optimal comparison condition. It has been suggested to directly compare negative and positive stimuli [64]. However, participants rated negative stimuli as more arousing than positive ones, even when the authors had matched negative and positive stimuli according to standardized ratings of this dimension [192]. Thus, in these cases, the confounder remained that stimuli of higher arousal attract more attention [193, 194]. With respect to brain imaging studies, it also supervenes that specific pathways for valence and arousal dimensions could hardly be identified [9]. A suggestion for future research could be to include positive stimuli and report and control for valence and arousal ratings of the stimuli rated after participation by the participants.

In summary, the methodological heterogeneities in the reported and additional studies suggest that sample characteristics, task and stimulus characteristics may bias attention-emotion interactions. Well-powered and well-controlled study designs may be able to examine the influence of these variables in future studies.

\section{Conclusions}

This review first provided an overview of the concept and neural correlates of attention-emotion interactions in the general population. Heterogeneous evidence was presented to demonstrate that it is not yet clear whether emotional dysregulation in those with BPD is reflected by higher distractibility by emotional stimuli. This review then summarized evidence for three selected, not yet well-studied, factors (i.e., dissociation, self-reference, and psychotherapeutic interventions), which are suggested to modulate attention-emotion interactions in those with BPD. They thus, in future, may allow a clearer understanding of the mechanisms influencing attention-emotion interactions in those with BPD. Figure 1 gives an overview of the main findings on attention-emotion interactions and dissociation, self-reference, and psychotherapeutic interventions. Dissociation was found to be associated with impaired maintenance of task continuation during the presentation of interfering emotional and neutral information in those with
BPD, as well as high recruitment of attentional resources associated with a blunted emotional response. With respect to self-reference, this review points out that individuals with BPD show a marked negative self-concept and low selfesteem, which may be unnstable, and increase attentionemotion interactions for negative stimuli. Social or traumarelevant information may also provide more self-reference for individuals with BPD compared to healthy controls. After psychotherapeutic interventions, initial evidence suggests normalization of attention-emotion interactions. All of these processes not only influence attention-emotion interactions, but also influence how information is subsequently stored in long-term memory [14, 195], leading to biased representation of the outside world and, again, influencing attention-emotion interactions. As evidence is often heterogeneous, the proposed influences need to be considered as working hypotheses for future research. In this research, several methodological challenges regarding sample, task, and stimulus characteristics need to be considered. If done so, dissociation, self-reference and symptom improvement via therapy may offer promising targets to understand the conflicting evidence found in attention-emotion interactions in those with BPD. This shall increase knowledge on the mechanisms of sensitivity to emotional stimuli as well as emotion regulation in BPD.

\section{Abbreviations \\ ACC: Anterior cingulate cortex; BPD: Borderline personality disorder; DBT: Dialectical behaviour therapy; dIPFC: Dorsolateral prefrontal cortex; e.g.: exempli gratia; for example; fMRI: functional magnetic resonance imaging; i.e.: id est; that is; IFG: Inferior frontal gyrus; PTSD: Post-traumatic stress disorder; VIPFC: Ventrolateral prefrontal cortex}

\section{Acknowledgements}

I thank Julia Herzog, Richelle Schaefer, and Christian Schmahl for their helpful comments on the manuscript.

Funding

Dachverband Dialektisch Behaviorale Therapie (DDBT) for manuscript publication fee.

Availability of data and materials

Not applicable.

\section{Authors' information}

The author is psychologist and postdoctoral researcher at her institution. One of her research interests are factors modulating emotion dysregulation in borderline personality disorder.

Competing interests

The author declares that she has no competing interests.

Consent for publication

Not applicable.

Ethics approval and consent to participate

Not applicable.

Received: 28 January 2016 Accepted: 27 September 2016

Published online: 04 October 2016 


\section{References}

1. Crowell SE, Beauchaine TP, Linehan MM. A biosocial developmental model of borderline personality: elaborating and extending Linehan's theory. Psychol Bull. 2009;135:495-510. doi:10.1037/a0015616.

2. Koenigsberg HW, Siever LJ, Lee H, Pizzarello S, New AS, Goodman M, et al. Neural correlates of emotion processing in borderline personality disorder. Psychiatry Res. 2009;172:192-9. doi:10.1016/j.pscychresns.2008.07.010.

3. Linehan MM, Kehrer CA. Borderline personality disorder. In: Barlow DH editor. Clinical handbook of psychological disorders: A step-by-step treatment manual. 2nd ed. New York: Guilford Press; 1993. p. 396-441.

4. Skodol AE, Gunderson JG, Shea MT, McGlashan TH, Morey LC, Sanislow CA et al. The Collaborative Longitudinal Personality Disorders Study (CLPS): overview and implications. J Pers Disord. 2005;19:487-504. doi:10.1521/pedi. 2005.19.5.487

5. Sanislow CA, Grilo CM, Morey LC, Bender DS, Skodol AE, Gunderson JG, et al. Confirmatory factor analysis of DSM-IV criteria for borderline personality disorder: findings from the collaborative longitudinal personality disorders study. Am J Psychiatry. 2002;159:284-90. doi:10.1176/appi.ajp.159.2.284.

6. Gross JJ, Thompson RA. Emotion regulation: conceptual foundations. In: Gross JJ, editor. Handbook of emotion regulation. New York: Guilford Press; 2007. p. 3-24.

7. Cisler JM, Olatunji BO. Emotion Regulation and Anxiety Disorders. Curr Psychiatry Rep. 2012;14:182-7. doi:10.1007/s11920-012-0262-2.

8. Taylor SF, Liberzon I. Neural correlates of emotion regulation in psychopathology. Trends Cogn Sci. 2007;11:413-8. doi:10.1016/j.tics.2007.08. 006.

9. Dolcos F, Wang L, Mather M. Current research and emerging directions in emotion-cognition interactions. Front Integr Neurosci. 2014;8:83. doi:10.3389/fnint.2014.00083.

10. Carretie L. Exogenous (automatic) attention to emotional stimuli: a review. Cogn Affect Behav Neurosci. 2014;14:1228-58. doi:10.3758/s13415-014-0270-2.

11. Iordan AD, Dolcos S, Dolcos F. Neural signatures of the response to emotional distraction: a review of evidence from brain imaging investigations. Front Hum Neurosci. 2013;7:200. doi:10.3389/fnhum.2013.00200.

12. Okon-Singer $H$, Hendler T, Pessoa L, Shackman AJ. The neurobiology of emotion-cognition interactions: fundamental questions and strategies for future research. Front Hum Neurosci. 2015;9:58. doi:10.3389/fnhum.2015. 00058.

13. Mohanty A, Sussman TJ. Top-down modulation of attention by emotion. Front Hum Neurosci. 2013;7:102. doi:10.3389/fnhum.2013.00102.

14. Hamann S. Cognitive and neural mechanisms of emotional memory. Trends Cogn Sci. 2001;5:394-400. doi:10.1016/S1364-6613(00)01707-1.

15. Pourtois $G$, Schettino A, Vuilleumier P. Brain mechanisms for emotional influences on perception and attention: what is magic and what is not. Biol Psychol. 2013;92:492-512. doi:10.1016/j.biopsycho.2012.02.007.

16. Miller EK, Cohen JD. An integrative theory of prefrontal cortex function. Annu Rev Neurosci. 2001;24:167-202. doi:10.1146/annurev.neuro.24.1.167.

17. Desimone R, Duncan J. Neural mechanisms of selective visual attention. Annu Rev Neurosci. 1995;18:193-222. doi:10.1146/annurev.ne.18.030195.001205.

18. Kalanthroff $E$, Cohen N, Henik A. Stop feeling: inhibition of emotional interference following stop-signal trials. Front Hum Neurosci. 2013;7:78. doi:10.3389/fnhum.2013.00078.

19. Shackman AJ, Salomons TV, Slagter HA, Fox AS, Winter JJ, Davidson RJ. The integration of negative affect, pain, and cognitive control in the cingulate cortex. Nat Rev Neurosci. 2011;12:154-67. doi:10.1038/nrn2994.

20. Pessoa L, Padmala S, Kenzer A, Bauer A. Interactions between cognition and emotion during response inhibition. Emotion. 2012;12:192-7. doi:10.1037/ a0024109.

21. van Ast VA, Spicer J, Smith EE, Schmer-Galunder S, Liberzon I, Abelson JL, et al. Brain mechanisms of social threat effects on working memory. Cereb Cortex. 2016;26:544-56. doi:10.1093/cercor/bhu206.

22. Okon-Singer H, Mehnert J, Hoyer J, Hellrung L, Schaare HL, Dukart J, et al. Neural control of vascular reactions: impact of emotion and attention. J Neurosci. 2014;34:4251-9. doi:10.1523/jneurosci.0747-13.2014.

23. Vuilleumier P, Armony JL, Driver J, Dolan RJ. Effects of attention and emotion on face processing in the human brain: an event-related fMRI study. Neuron. 2001;30:829-41. doi:10.1016/S0896-6273(01)00328-2.

24. Ochsner KN, Gross JJ. The cognitive control of emotion. Trends Cogn Sci. 2005;9:242-9. doi:10.1016/j.tics.2005.03.010.

25. Etkin A, Buchel C, Gross JJ. The neural bases of emotion regulation. Nat Rev Neurosci. 2015;16:693-700. doi:10.1038/nrn4044.
26. Thiruchselvam R, Blechert J, Sheppes G, Rydstrom A, Gross JJ. The temporal dynamics of emotion regulation: an EEG study of distraction and reappraisal. Biol Psychol. 2011;87:84-92. doi:10.1016/j.biopsycho. 2011.02.009.

27. Schönfelder S, Kanske P, Heissler J, Wessa M. Time course of emotionrelated responding during distraction and reappraisal. Soc Cogn Affect Neurosci. 2014;9:1310-9. doi:10.1093/scan/nst116.

28. McRae K, Hughes B, Chopra S, Gabrieli JD, Gross JJ, Ochsner KN. The neural bases of distraction and reappraisal. J Cogn Neurosci. 2010;22:248-62. doi:10.1162/jocn.2009.21243.

29. Kanske P, Heissler J, Schönfelder S, Bongers A, Wessa M. How to regulate emotion? Neural networks for reappraisal and distraction. Cereb Cortex. 2011;21:1379-88. doi:10.1093/cercor/bhq216.

30. Lieberman MD, Inagaki TK, Tabibnia G, Crockett MJ. Subjective responses to emotional stimuli during labeling, reappraisal, and distraction. Emotion. 2011;11:468-80. doi:10.1037/a0023503.

31. Rusting CL, Nolen-Hoeksema S. Regulating responses to anger: effects of rumination and distraction on angry mood. J Pers Soc Psychol. 1998;74:790-803. doi:10.1037/0022-3514.74.3.790.

32. Morrow J, Nolen-Hoeksema S. Effects of responses to depression on the remediation of depressive affect. J Pers Soc Psychol. 1990;58:519-27. doi:10.1037/0022-3514.58.3.519

33. Bennett P, Phelps C, Brain K, Hood K, Gray J. A randomized controlled trial of a brief self-help coping intervention designed to reduce distress when awaiting genetic risk information. J Psychosom Res. 2007;63:59-64. doi:10.1016/j.jpsychores.2007.01.016.

34. Fennell MJ, Teasdale JD. Effects of distraction on thinking and affect in depressed patients. Br J Clin Psychol. 1984;23(Pt 1):65-6. doi:10.1111/j.20448260.1984.tb00628.x.

35. Sheppes G, Meiran N. Better late than never? On the dynamics of online regulation of sadness using distraction and cognitive reappraisal. Pers Soc Psychol Bull. 2007;33:1518-32. doi:10.1177/0146167207305537.

36. Nee DE, Brown JW, Askren MK, Berman MG, Demiralp E, Krawitz A, et al. A meta-analysis of executive components of working memory. Cereb Cortex. 2013;23:264-82. doi:10.1093/cercor/bhs007.

37. Niendam TA, Laird AR, Ray KL, Dean YM, Glahn DC, Carter CS. Meta-analytic evidence for a superordinate cognitive control network subserving diverse executive functions. Cogn Affect Behav Neurosci. 2012;12:241-68. doi:10.3758/s13415-011-0083-5.

38. Rottschy C, Langner R, Dogan I, Reetz K, Laird AR, Schulz JB, et al. Modelling neural correlates of working memory: a coordinate-based meta-analysis. Neuroimage. 2012;60:830-46. doi:10.1016/j.neuroimage.2011.11.050.

39. Dörfel D, Lamke JP, Hummel F, Wagner U, Erk S, Walter H. Common and differential neural networks of emotion regulation by detachment, reinterpretation, distraction, and expressive suppression: a comparative fMR investigation. Neuroimage. 2014;101:298-309. doi:10.1016/j.neuroimage. 2014.06.051

40. Costafreda SG, Brammer MJ, David AS, Fu CH. Predictors of amygdala activation during the processing of emotional stimuli: a meta-analysis of 385 PET and fMRI studies. Brain Res Rev. 2008;58:57-70. doi:10.1016/j. brainresrev.2007.10.012.

41. Vytal K, Hamann S. Neuroimaging support for discrete neural correlates of basic emotions: a voxel-based meta-analysis. J Cogn Neurosci. 2010;22: 2864-85. doi:10.1162/jocn.2009.21366.

42. Lindquist KA, Wager TD, Kober H, Bliss-Moreau E, Barrett LF. The brain basis of emotion: a meta-analytic review. Behav Brain Sci. 2012;35:121-43. doi:10.1017/s0140525x11000446.

43. Kober H, Barrett LF, Joseph J, Bliss-Moreau E, Lindquist K, Wager TD. Functional grouping and cortical-subcortical interactions in emotion: a meta-analysis of neuroimaging studies. Neuroimage. 2008;42:998-1031. doi:10.1016/j.neuroimage.2008.03.059.

44. Phan KL, Wager T, Taylor SF, Liberzon I. Functional neuroanatomy of emotion: a meta-analysis of emotion activation studies in PET and FMRI. Neuroimage. 2002;16:331-48. doi:10.1006/nimg.2002.1087.

45. Carretie L, Kessel D, Carboni A, Lopez-Martin S, Albert J, Tapia M, et al. Exogenous attention to facial vs non-facial emotional visual stimuli. Soc Cogn Affect Neurosci. 2013;8:764-73. doi:10.1093/scan/nss068.

46. Schönwald LI, Müller MM. Slow biasing of processing resources in early visual cortex is preceded by emotional cue extraction in emotion-attention competition. Hum Brain Mapp. 2014;35:1477-90. doi:10.1002/hbm.22267. 
47. Carretie L, Ruiz-Padial E, Lopez-Martin S, Albert J. Decomposing unpleasantness: differential exogenous attention to disgusting and fearful stimuli. Biol Psychol. 2011;86:247-53. doi:10.1016/j.biopsycho.2010. 12.005 .

48. Mitchell DG, Nakic M, Fridberg D, Kamel N, Pine DS, Blair RJ. The impact of processing load on emotion. Neuroimage. 2007;34:1299-309. doi:10.1016/j. neuroimage.2006.10.012.

49. Haas BW, Omura K, Amin Z, Constable RT, Canli T. Functional connectivity with the anterior cingulate is associated with extraversion during the emotional Stroop task. Soc Neurosci. 2006;1:16-24. doi:10.1080/ 17470910600650753 .

50. Ochsner KN, Hughes B, Robertson ER, Cooper JC, Gabrieli JD. Neural systems supporting the control of affective and cognitive conflicts. J Cogn Neurosci. 2009;21:1842-55. doi:10.1162/jocn.2009.21129.

51. Egner T, Etkin A, Gale S, Hirsch J. Dissociable neural systems resolve conflict from emotional versus nonemotional distracters. Cereb Cortex. 2008;18: 1475-84. doi:10.1093/cercor/bhm179.

52. Kanske P, Kotz SA. Emotion speeds up conflict resolution: a new role for the ventral anterior cingulate cortex? Cereb Cortex. 2011;21:911-9. doi:10.1093/ cercor/bhq157.

53. Kanske P, Kotz SA. Emotion triggers executive attention: anterior cingulate cortex and amygdala responses to emotional words in a conflict task. Hum Brain Mapp. 2011;32:198-208. doi:10.1002/hbm.21012.

54. Whalen PJ, Bush G, McNally RJ, Wilhelm S, McInerney SC, Jenike MA, et al. The emotional counting Stroop paradigm: a functional magnetic resonance imaging probe of the anterior cingulate affective division. Biol Psychiatry. 1998:44:1219-28. doi:10.1016/S0006-3223(98)00251-0.

55. Etkin A, Egner T, Peraza DM, Kandel ER, Hirsch J. Resolving emotional conflict: a role for the rostral anterior cingulate cortex in modulating activity in the amygdala. Neuron. 2006;51:871-82. doi:10.1016/.neuron.2006.07.029.

56. Bush G, Luu P, Posner Ml. Cognitive and emotional influences in anterior cingulate cortex. Trends Cogn Sci. 2000;4:215-22. doi:10.1016/S1364 6613(00)01483-2

57. Mohanty A, Engels AS, Herrington JD, Heller W, Ho MH, Banich MT, et al. Differential engagement of anterior cingulate cortex subdivisions for cognitive and emotional function. Psychophysiology. 2007:44:343-51. doi:10.1111/j.1469-8986.2007.00515.x.

58. Dolcos F, Kragel P, Wang L, McCarthy G. Role of the inferior frontal cortex in coping with distracting emotions. Neuroreport. 2006;17:1591-4. doi:10.1097/ 01.wnr.0000236860.24081.be

59. Dolcos F, McCarthy G. Brain systems mediating cognitive interference by emotional distraction. J Neurosci. 2006:26:2072-9. doi:10.1523/JNEUROSCI. 5042-05.2006

60. Compton RJ, Banich MT, Mohanty A, Milham MP, Herrington J, Miller GA, et al. Paying attention to emotion: an fMRI investigation of cognitive and emotional stroop tasks. Cogn Affect Behav Neurosci. 2003;3:81-96. doi:10.3758/cabn.3.2.81.

61. Herrington JD, Mohanty A, Koven NS, Fisher JE, Stewart JL, Banich MT, et al. Emotion-modulated performance and activity in left dorsolateral prefrontal cortex. Emotion. 2005:5:200-7. doi:10.1037/1528-3542.5.2.200.

62. Schulze L, Schmahl C, Niedtfeld I. Neural correlates of disturbed emotion processing in borderline personality disorder: a multimodal meta-analysis. Biol Psychiatry. 2016;79:97-106. doi:10.1016/j.biopsych.2015.03.027.

63. Krause-Utz A, Winter D, Niedtfeld I, Schmahl C. The latest neuroimaging findings in borderline personality disorder. Curr Psychiatry Rep. 2014;16:438. doi:10.1007/s1 1920-014-0438-z.

64. van Zutphen L, Siep N, Jacob GA, Goebel R, Arntz A. Emotional sensitivity, emotion regulation and impulsivity in borderline personality disorder: a critical review of fMRI studies. Neurosci Biobehav Rev. 2015;51c:64-76. doi:10.1016/j.neubiorev.2015.01.001.

65. Stiglmayr CE, Grathwol T, Linehan MM, Ihorst G, Fahrenberg J, Bohus M. Aversive tension in patients with borderline personality disorder: a computer-based controlled field study. Acta Psychiatr Scand. 2005;111:372-9. doi:10.1111/j.1600-0447.2004.00466.x.

66. Reitz S, Krause-Utz A, Pogatzki-Zahn EM, Ebner-Priemer U, Bohus M, Schmahl C. Stress regulation and incision in borderline personality disordera pilot study modeling cutting behavior. J Pers Disord. 2012;26:605-15. doi:10.1521/pedi_2012_26_025.

67. Santangelo P, Reinhard I, Mussgay L, Steil R, Sawitzki G, Klein C, et al. Specificity of affective instability in patients with borderline personality disorder compared to posttraumatic stress disorder, bulimia nervosa, and healthy controls. J Abnorm Psychol. 2014;123:258-72. doi:10.1037/a0035619.
68. Stiglmayr CE, Shapiro DA, Stieglitz RD, Limberger MF, Bohus M. Experience of aversive tension and dissociation in female patients with borderline personality disorder-a controlled study. J Psychiatr Res. 2001;35(2):111-8. doi:10.1016/S0022-3956(01)00012-7.

69. Arntz A, Appels C, Sieswerda S. Hypervigilance in borderline disorder: a test with emotional Stroop paradigm. J Pers Disord. 2000;14(4):366-73. doi:10.1521/pedi.2000.14.4.366.

70. Sieswerda S, Arntz A, Mertens I, Vertommen S. Hypervigilance in patients with borderline personality disorder: specificity, automaticity, and predictors. Behav Res Ther. 2007:45:1011-24. doi:10.1016/j.brat.2006.07.012.

71. Wingenfeld K, Mensebach C, Rullkoetter N, Schlosser N, Schaffrath C, Woermann FG, et al. Attentional bias to personally relevant words in borderline personality disorder is strongly related to comorbid posttraumatic stress disorder. J Pers Disord. 2009;23:141-55. doi:10.1521/pedi.2009.23.2.141.

72. Hurlemann R, Hawellek B, Maier W, Dolan RJ. Enhanced emotion-induced amnesia in borderline personality disorder. Psychol Med. 2007;37:971-81. doi:10.1017/50033291706009792.

73. Mensebach C, Wingenfeld K, Driessen M, Rullkoetter N, Schlosser N, Steil C, et al. Emotion-induced memory dysfunction in borderline personality disorder. Cogn Neuropsychiatry. 2009;14:524-41. doi:10.1080/ 13546800903049853

74. Krause-Utz A, Elzinga BM, Oei NY, Spinhoven P, Bohus M, Schmahl C. Susceptibility to distraction by social cues in borderline personality disorder. Psychopathology. 2014;47:148-57. doi:10.1159/000351740.

75. Domes G, Winter B, Schnell K, Vohs K, Fast K, Herpertz SC. The influence of emotions on inhibitory functioning in borderline personality disorder. Psychol Med. 2006;36:1163-72. doi:10.1017/S0033291706007756.

76. Minzenberg MJ, Poole JH, Vinogradov S. A neurocognitive model of borderline personality disorder: effects of childhood sexual abuse and relationship to adult social attachment disturbance. Dev Psychopathol. 2008; 20:341-68. doi:10.1017/S0954579408000163.

77. Sprock J, Rader TJ, Kendall JP, Yoder CY. Neuropsychological functioning in patients with borderline personality disorder. J Clin Psychol. 2000;56:1587600. doi:10.1002/1097-4679(200012)56:12<1587:aid-9>3.0.co;2-g.

78. Wingenfeld K, Rullkoetter N, Mensebach C, Beblo T, Mertens M, Kreisel S, et al. Neural correlates of the individual emotional Stroop in borderline personality disorder. Psychoneuroendocrinology. 2009;34:571-86. doi:10. 1016/j.psyneuen.2008.10.024.

79. Krause-Utz A, Oei NY, Niedtfeld I, Bohus M, Spinhoven P, Schmahl C, et al. Influence of emotional distraction on working memory performance in borderline personality disorder. Psychol Med. 2012;42:2181-92. doi:10.1017/ S0033291712000153

80. Prehn K, Schulze L, Rossmann S, Berger C, Vohs K, Fleischer M, et al. Effects of emotional stimuli on working memory processes in male criminal offenders with borderline and antisocial personality disorder. World J Biol Psychiatry. 2013;14:71-8. doi:10.3109/15622975.2011.584906.

81. Winter D, Krause-Utz A, Lis S, Chiu CD, Lanius RA, Schriner F, et al. Dissociation in borderline personality disorder: disturbed cognitive and emotional inhibition and its neural correlates. Psychiatry Res. 2015;233:339-51. doi:10.1016/.jpscychresns.2015.05.018.

82. Silbersweig D, Clarkin JF, Goldstein M, Kernberg OF, Tuescher O, Levy KN, et al. Failure of frontolimbic inhibitory function in the context of negative emotion in borderline personality disorder. Am J Psychiatry. 2007;164:1832-41. doi:10.1176/appi.ajp.2007.06010126.

83. Minzenberg MJ, Fan J, New AS, Tang CY, Siever LJ. Fronto-limbic dysfunction in response to facial emotion in borderline personality disorder: an event-related fMRI study. Psychiatry Res. 2007;155:231-43. doi:10.1016/j.pscychresns.2007.03.006

84. Krause-Utz A, Elzinga BM, Oei NY, Paret C, Niedtfeld I, Spinhoven P, et al. Amygdala and dorsal anterior cingulate connectivity during an emotional working memory task in borderline personality disorder patients with interpersonal trauma history. Front Hum Neurosci. 2014;8:848. doi:10.3389/fnhum.2014.00848.

85. Winter D, Herbert C, Koplin K, Schmahl C, Bohus M, Lis S. Negative evaluation bias for positive self-referential information in borderline personality disorder. PLoS One. 2015;10:e0117083. doi:10.1371/journal.pone.0117083.

86. Winter D, Koplin K, Schmahl C, Bohus M, Lis S. Evaluation and memory of social events in borderline personality disorder: effects of valence and selfreferential context. Psychiatry Res. 2016;240:19-25. doi:10.1016/.jpsychres. 2016.03.042 
87. Sieswerda S, Arntz A, Kindt M. Successful psychotherapy reduces hypervigilance in borderline personality disorder. Behav Cogn Psychother. 2007;35:387. doi:10.1017/s1352465807003694.

88. Haaland VO, Landro NI. Pathological dissociation and neuropsychological functioning in borderline personality disorder. Acta Psychiatr Scand. 2009; 119:383-92. doi:10.1111/j.1600-0447.2008.01323.x

89. Barnow S, Limberg A, Stopsack M, Spitzer C, Grabe HJ, Freyberger HJ, et al. Dissociation and emotion regulation in borderline personality disorder. Psychol Med. 2012;42:783-94. doi:10.1017/S0033291711001917.

90. Krause-Utz A, Veer IM, Rombouts SA, Bohus M, Schmahl C, Elzinga BM. Amygdala and anterior cingulate resting-state functional connectivity in borderline personality disorder patients with a history of interpersonal trauma. Psychol Med. 2014;44:2889-901. doi:10.1017/s0033291714000324.

91. Simeon D, Guralnik O, Schmeidler J, Sirof B, Knutelska M. The role of childhood interpersonal trauma in depersonalization disorder. Am J Psychiatry. 2001;158:1027-33. doi:10.1176/appi.ajp.158.7.1027.

92. APA. Diagnostic and statistical manual of mental disorders: DSM-5. 5th ed. Arlington: American Psychiatric Association; 2013.

93. Korzekwa MI, Dell PF, Links PS, Thabane L, Fougere P. Dissociation in borderline personality disorder: a detailed look. J Trauma Dissociation. 2009; 10:346-67. doi:10.1080/15299730902956838

94. Stiglmayr CE, Ebner-Priemer UW, Bretz J, Behm R, Mohse M, Lammers CH, et al. Dissociative symptoms are positively related to stress in borderline personality disorder. Acta Psychiatr Scand. 2008;117:139-47. doi:10.1111/j. 1600-0447.2007.01126.x

95. Ludascher P, Bohus M, Lieb K, Philipsen A, Jochims A, Schmahl C. Elevated pain thresholds correlate with dissociation and aversive arousal in patients with borderline personality disorder. Psychiatry Res. 2007;149:291-6. doi:10.1016/j.psychres.2005.04.009.

96. Ludascher P, Valerius G, Stiglmayr C, Mauchnik J, Lanius RA, Bohus M, et al. Pain sensitivity and neural processing during dissociative states in patients with borderline personality disorder with and without comorbid posttraumatic stress disorder: a pilot study. J Psychiatry Neurosci. 2010;35: 177-84. doi:10.1503/jpn.090022.

97. Ebner-Priemer UW, Mauchnik J, Kleindienst N, Schmahl C, Peper M, Rosenthal MZ, et al. Emotional learning during dissociative states in borderline personality disorder. J Psychiatry Neurosci. 2009;34:214-22.

98. Ebner-Priemer UW, Badeck S, Beckmann C, Wagner A, Feige B, Weiss I, et al. Affective dysregulation and dissociative experience in female patients with borderline personality disorder: a startle response study. J Psychiatr Res. 2005;39:85-92. doi:10.1016/j.jpsychires.2004.05.001.

99. Hazlett EA, Zhang J, New AS, Zelmanova Y, Goldstein KE, Haznedar MM, et al. Potentiated amygdala response to repeated emotional pictures in borderline personality disorder. Biol Psychiatry. 2012;72:448-56. doi:10.1016/j. biopsych.2012.03.027.

100. Lanius RA, Vermetten E, Loewenstein RJ, Brand B, Schmahl C, Bremner JD, et al. Emotion modulation in PTSD: Clinical and neurobiological evidence for a dissociative subtype. Am J Psychiatry. 2010;167:640-7. doi:10.1176/appi.ajp. 2009.09081168

101. Lanius RA, Brand B, Vermetten E, Frewen PA, Spiegel D. The dissociative subtype of posttraumatic stress disorder: rationale, clinical and neurobiological evidence, and implications. Depress Anxiety. 2012;29:701-8. doi:10.1002/da.21889.

102. Sierra M, Berrios GE. Depersonalization: neurobiological perspectives. Biol Psychiatry. 1998;44:898-908. doi:10.1016/S0006-3223(98)00015-8.

103. Engelmann JB, Pessoa L. Motivation sharpens exogenous spatial attention. Emotion. 2007;7:668-74. doi:10.1037/1528-3542.7.3.668.

104. Kristjansson A, Sigurjonsdottir $O$, Driver J. Fortune and reversals of fortune in visual search: reward contingencies for pop-out targets affect search efficiency and target repetition effects. Atten Percept Psychophys. 2010;72: 1229-36. doi:10.3758/app.72.5.1229.

105. Della Libera C, Chelazzi L. Visual selective attention and the effects of monetary rewards. Psychol Sci. 2006;17:222-7. doi:10.1111/j.1467-9280.2006.01689.x.

106. Vogt J, De Houwer J, Moors A, Van Damme S, Crombez G. The automatic orienting of attention to goal-relevant stimuli. Acta Psychol (Amst). 2010; 134:61-9. doi:10.1016/j.actpsy.2009.12.006.

107. Beeney JE, Hallquist MN, Ellison WD, Levy KN. Self-other disturbance in borderline personality disorder: neural, self-report, and performance-based evidence. Pers Disord. 2016;7:28-39. doi:10.1037/per0000127.

108. Doll A, Sorg C, Manoliu A, Woller A, Meng C, Forstl H, et al. Shifted intrinsic connectivity of central executive and salience network in borderline personality disorder. Front Hum Neurosci. 2013;7:727. doi:10.3389/fnhum.2013.00727.
109. Wolf RC, Sambataro F, Vasic N, Schmid M, Thomann PA, Bienentreu SD, et al. Aberrant connectivity of resting-state networks in borderline personality disorder. J Psychiatry Neurosci. 2011;36:402-11. doi:10.1503/ jpn.100150.

110. Auerbach RP, Tarlow N, Bondy E, Stewart JG, Aguirre B, Kaplan C, et al. Electrocortical reactivity during self-referential processing in female youth with borderline personality disorder. Biol Psychiatry Cogn Neurosci Neuroimaging. 2016;1:335-44. doi:10.1016/j.bpsc.2016.04.004.

111. Herbert $C$, Herbert BM, Ethofer T, Pauli P. His or mine? The time course of self-other discrimination in emotion processing. Soc Neurosci. 2011;6:27788. doi:10.1080/17470919.2010.523543.

112. Herbert C, Pauli P, Herbert BM. Self-reference modulates the processing of emotional stimuli in the absence of explicit self-referential appraisal instructions. Soc Cogn Affect Neurosci. 2011;6:653-61. doi:10.1093/scan/nsq082.

113. Herbert C, Kissler J, Junghofer M, Peyk P, Rockstroh B. Processing of emotional adjectives: evidence from startle EMG and ERPs. Psychophysiology. 2006;43:197-206. doi:10.1111/j.1469-8986.2006.00385.x.

114. Kissler J, Herbert C, Winkler I, Junghofer M. Emotion and attention in visual word processing: an ERP study. Biol Psychol. 2009;80:75-83. doi:10.1016/j. biopsycho.2008.03.004

115. Watson LA, Dritschel B, Obonsawin MC, Jentzsch I. Seeing yourself in a positive light: brain correlates of the self-positivity bias. Brain Res. 2007;1152: 106-10. doi:10.1016/j.brainres.2007.03.049.

116. Lynum LI, Wilberg T, Karterud S. Self-esteem in patients with borderline and avoidant personality disorders. Scand J Psychol. 2008;49:469-77. doi:10.1111/ j.1467-9450.2008.00655.x.

117. Bungert M, Liebke L, Thome J, Haeussler K, Bohus M, Lis S. Rejection sensitivity and symptom severity in patients with borderline personality disorder: effects of childhood maltreatment and self-esteem. Borderline Pers Disord Emot Dysregul. 2015:2:4. doi:10.1186/s40479-015-0025-x. eCollection 2015.

118. Vater A, Schroder-Abe M, Weissgerber S, Roepke S, Schutz A. Self-concept structure and borderline personality disorder: evidence for negative compartmentalization. J Behav Ther Exp Psychiatry. 2015;46:50-8. doi:10. 1016/j.jbtep.2014.08.003

119. Kopala-Sibley DC, Zuroff DC, Russell JJ, Moskowitz DS, Paris J. Understanding heterogeneity in borderline personality disorder: differences in affective reactivity explained by the traits of dependency and self-criticism. J Abnorm Psychol. 2012;121:680-91. doi:10.1037/a0028513.

120. Rusch N, Lieb K, Gottler I, Hermann C, Schramm E, Richter H, et al. Shame and implicit self-concept in women with borderline personality disorder. Am J Psychiatry. 2007;164:500-8. doi:10.1176/appi.ajp.164.3.500.

121. Dyer A, Borgmann E, Feldmann REJ, Kleindienst N, Priebe K, Bohus M, et al. Body image disturbance in patients with borderline personality disorder: impact of eating disorders and perceived childhood sexual abuse. Body Image. 2013;10:220-5. doi:10.1016/j.bodyim.2012.12.007.

122. Sansone RA, Chu JW, Wiederman MW. Body image and borderline personality disorder among psychiatric inpatients. Compr Psychiatry. 2010; 51:579-84. doi:10.1016/j.comppsych.2010.04.001.

123. Zeigler-Hill V, Abraham J. Borderline personality features: instability of selfesteem and affect. J Soc Clin Psychol. 2006;25:668-87. doi:10.1521/jscp.2006. 25.6.668.

124. Tolpin LH, Gunthert KC, Cohen LH, O'Neill SC. Borderline personality features and instability of daily negative affect and self-esteem. J Pers. 2004:72:11137. doi:10.1111/j.0022-3506.2004.00258.x.

125. Neacsiu AD, Herr NR, Fang CM, Rodriguez MA, Rosenthal MZ. Identity disturbance and problems with emotion regulation are related constructs across diagnoses. J Clin Psychol. 2015;71:346-61. doi:10.1002/jclp.22141.

126. Fuchs T. Fragmented selves: temporality and identity in borderline personality disorder. Psychopathology. 2007:40:379-87. doi:10.1159/ 000106468.

127. Zanarini MC, Williams AA, Lewis RE, Reich RB, Vera SC, Marino MF, et al. Reported pathological childhood experiences associated with the development of borderline personality disorder. Am J Psychiatry. 1997;154:1101-6. doi:10.1176/ajp.154.8.1101.

128. Liotti G, Pasquini P. Predictive factors for borderline personality disorder: patients' early traumatic experiences and losses suffered by the attachment figure. The Italian Group for the Study of Dissociation. Acta Psychiatr Scand. 2000;102:282-9. doi:10.1034/j.1600-0447.2000.102004282.x.

129. Pietrek C, Elbert T, Weierstall R, Muller O, Rockstroh B. Childhood adversities in relation to psychiatric disorders. Psychiatry Res. 2013;206:103-10. doi:10.1016/j.psychres.2012.11.003. 
130. Golier JA, Yehuda R, Bierer LM, Mitropoulou V, New AS, Schmeidler J, et al. The relationship of borderline personality disorder to posttraumatic stress disorder and traumatic events. Am J Psychiatry. 2003;160:2018-24. doi:10.1176/appi.ajp.160.11.2018.

131. Grant BF, Chou SP, Goldstein RB, Huang B, Stinson FS, Saha TD, et al. Prevalence, correlates, disability, and comorbidity of DSM-IV borderline personality disorder: results from the Wave 2 National Epidemiologic Survey on Alcohol and Related Conditions. J Clin Psychiatry. 2008;69:533-45.

132. Lenzenweger MF, Lane MC, Loranger AW, Kessler RC. DSM-IV personality disorders in the National Comorbidity Survey Replication. Biol Psychiatry. 2007;62:553-64. doi:10.1016/j.biopsych.2006.09.019.

133. Northoff G, Heinzel A, de Greck M, Bermpohl F, Dobrowolny H, Panksepp J. Selfreferential processing in our brain - a meta-analysis of imaging studies on the self. Neuroimage. 2006;31:440-57. doi:10.1016/j.neuroimage.2005.12.002.

134. Kliem S, Kroger C, Kosfelder J. Dialectical behavior therapy for borderline personality disorder: a meta-analysis using mixed-effects modeling. J Consult Clin Psychol. 2010;78:936-51. doi:10.1037/a0021015.

135. Stoffers JM, Vollm BA, Rucker G, Timmer A, Huband N, Lieb K. Psychological therapies for people with borderline personality disorder. Cochrane Database Syst Rev. 2012;8:CD005652. doi:10.1002/14651858.CD005652.pub2.

136. Burmeister K, Höschel K, von Auer AK, Reiske S, Schweiger U, Sipos V, et al. Dialektisch Behaviorale Therapie-Weiterentwicklungen und empirische Evidenz. Psychiat Prax. 2014;41:242-9. doi:10.1055/s-0034-1369905.

137. Winter D, Niedtfeld I, Schmitt R, Bohus M, Schmahl C, Herpertz SC. Neural correlates of distraction in borderline personality disorder before and after dialectical behavior therapy. Eur Arch Psychiatry Clin Neurosci. 2016. epub ahead of print. doi:10.1007/s00406-016-0689-2.

138. Perez DL, Vago DR, Pan H, Root J, Tuescher O, Fuchs BH, et al. Frontolimbic neural circuit changes in emotional processing and inhibitory control associated with clinical improvement following transference-focused psychotherapy in borderline personality disorder. Psychiatry Clin Neurosci. 2016:70:51-61. doi:10.1111/pen.12357.

139. Yang Y, Kircher T, Straube B. The neural correlates of cognitive behavioral therapy: recent progress in the investigation of patients with panic disorder. Behav Res Ther. 2014;62:88-96. doi:10.1016/j.brat.2014.07.011.

140. Barsaglini A, Sartori G, Benetti S, Pettersson-Yeo W, Mechelli A. The effects of psychotherapy on brain function: a systematic and critical review. Prog Neurobiol. 2014;114:1-14. doi:10.1016/j.pneurobio.2013.10.006.

141. Messina I, Sambin M, Palmieri A, Viviani R. Neural correlates of psychotherapy in anxiety and depression: a meta-analysis. PLoS One. 2013;8:e74657. doi:10.1371/journal.pone.0074657.

142. Weingarten CP, Strauman TJ. Neuroimaging for psychotherapy research: current trends. Psychother Res. 2015;25:185-213. doi:10.1080/10503307.2014.883088.

143. Goodman M, Carpenter D, Tang CY, Goldstein KE, Avedon J, Fernandez N, et al. Dialectical behavior therapy alters emotion regulation and amygdala activity in patients with borderline personality disorder. J Psychiatr Res. 2014:57:108-16. doi:10.1016/j.jpsychires.2014.06.020.

144. Schnell K, Herpertz SC. Effects of dialectic-behavioral-therapy on the neural correlates of affective hyperarousal in borderline personality disorder. J Psychiatr Res. 2007;41:837-47. doi:10.1016/j.jpsychires.2006.08.011.

145. Schmitt R, Winter D, Niedtfeld I, Herpertz SC, Schmahl C. Effects of psychotherapy on neuronal correlates of reappraisal in female patients with borderline personality disorder. Biol Psychiatry Cogn Neurosci Neuroimaging. Epub ahead of print. doi:10.1016/j.bpsc.2016.07.003.

146. Linehan MM. Cognitive-behavioral treatment of borderline personality disorder. New York: Guilford Press; 1993.

147. Young JE, Klosko JS, Weishaar ME. Schema therapy: a practicioner's guide. New York: Guilford Press; 2003.

148. Weiskopf N. Real-time fMRI and its application to neurofeedback. Neuroimage. 2012;62:682-92. doi:10.1016/j.neuroimage.2011.10.009.

149. Bruhl AB, Scherpiet S, Sulzer J, Stampfli P, Seifritz E, Herwig U. Real-time neurofeedback using functional MRI could improve down-regulation of amygdala activity during emotional stimulation: a proof-of-concept study. Brain Topogr. 2014;27:138-48. doi:10.1007/s10548-013-0331-9.

150. Ruiz S, Lee S, Soekadar SR, Caria A, Veit R, Kircher T, et al. Acquired self-control of insula cortex modulates emotion recognition and brain network connectivity in schizophrenia. Hum Brain Mapp. 2013;34:200-12. doi:10.1002/hbm.21427.

151. Paret C, Kluetsch R, Ruf M, Demirakca T, Hoesterey S, Ende G, et al. Downregulation of amygdala activation with real-time $\mathrm{fMRI}$ neurofeedback in a healthy female sample. Front Behav Neurosci. 2014;8:299. doi:10.3389/fnbeh. 2014.00299
152. De Raedt R, Leyman L, Baeken C, Van Schuerbeek P, Luypaert R, Vanderhasselt MA, et al. Neurocognitive effects of HF-rTMS over the dorsolateral prefrontal cortex on the attentional processing of emotional information in healthy women: an event-related fMRI study. Biol Psychol. 2010;85:487-95. doi:10.1016/j.biopsycho.2010.09.015.

153. Vanderhasselt MA, De Raedt R, Brunoni AR, Campanha C, Baeken C, Remue J, et al. tDCS over the left prefrontal cortex enhances cognitive control for positive affective stimuli. PLoS One. 2013;8:e62219. doi:10.1371/journal.pone.0062219.

154. Boggio PS, Bermpohl F, Vergara AO, Muniz AL, Nahas FH, Leme PB, et al. Go-no-go task performance improvement after anodal transcranial DC stimulation of the left dorsolateral prefrontal cortex in major depression. J Affect Disord. 2007;101:91-8. doi:10.1016/j.jad.2006.10.026.

155. Bertsch K, Gamer M, Schmidt B, Schmidinger I, Walther S, Kastel T, et al. Oxytocin and reduction of social threat hypersensitivity in women with borderline personality disorder. Am J Psychiatry. 2013;170:1169-77. doi:10.1176/appi.ajp.2013.13020263.

156. Herpertz SC, Bertsch K. A new perspective on the pathophysiology of borderline personality disorder: a model of the role of oxytocin. Am J Psychiatry. 2015;172:840-51. doi:10.1176/appi.ajp.2015.15020216.

157. Carvalho Fernando S, Beblo T, Schlosser N, Terfehr K, Wolf OT, Otte C, et al. Acute glucocorticoid effects on response inhibition in borderline personality disorder. Psychoneuroendocrinology. 2013;38:2780-8. doi:10.1016/j.psyneuen.2013.07.008.

158. Di Simplicio M, Norbury R, Harmer CJ. Short-term antidepressant administration reduces negative self-referential processing in the medial prefrontal cortex in subjects at risk for depression. Mol Psychiatry. 2012;17: 503-10. doi:10.1038/mp.2011.16.

159. Di Simplicio M, Norbury R, Reinecke A, Harmer CJ. Paradoxical effects of short-term antidepressant treatment in fMRI emotional processing models in volunteers with high neuroticism. Psychol Med. 2014;44:241-52. doi:10.1017/s0033291713000731.

160. Godlewska BR, Norbury R, Selvaraj S, Cowen PJ, Harmer CJ. Short-term SSRI treatment normalises amygdala hyperactivity in depressed patients. Psychol Med. 2012;42:2609-17. doi:10.1017/s0033291712000591.

161. Sebastian A, Jung P, Krause-Utz A, Lieb K, Schmahl C, Tüscher O. Frontal dysfunctions of impulse control-a systematic review in borderline personality disorder and attention-deficit/hyperactivity disorder. Front Hum Neurosci. 2014;8:698. doi:10.3389/fnhum.2014.00698.

162. Elzinga BM, Phaf RH, Ardon AM, van Dyck R. Directed forgetting between, but not within, dissociative personality states. J Abnorm Psychol. 2003;112: 237-43. doi:10.1037/0021-843x.112.2.237.

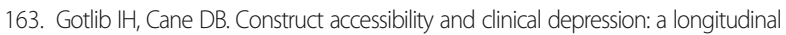
investigation. J Abnorm Psychol. 1987;96:199-204. doi:10.1037/0021-843X.96.3.199.

164. Wagner G, Schachtzabel C, Peikert G, Bar KJ. The neural basis of the abnormal self-referential processing and its impact on cognitive control in depressed patients. Hum Brain Mapp. 2015;36:2781-94. doi:10.1002/hbm.22807.

165. Nejad AB, Fossati $P$, Lemogne $C$. Self-referential processing, rumination, and cortical midline structures in major depression. Front Hum Neurosci. 2013;7: 666. doi:10.3389/fnhum.2013.00666.

166. Vogt J, Lozo L, Koster EH, De Houwer J. On the role of goal relevance in emotional attention: disgust evokes early attention to cleanliness. Cogn Emot. 2011;25:466-77. doi:10.1080/02699931.2010.532613.

167. Bishop SJ, Duncan J, Lawrence AD. State anxiety modulation of the amygdala response to unattended threat-related stimuli. J Neurosci. 2004; 24:10364-8. doi:10.1523/jneurosci.2550-04.2004.

168. Mather M, Sutherland MR. Arousal-biased competition in perception and memory. Perspect Psychol Sci. 2011;6:114-33. doi:10.1177/1745691611400234.

169. Stevens JS, Hamann S. Sex differences in brain activation to emotional stimuli: a meta-analysis of neuroimaging studies. Neuropsychologia. 2012;50: 1578-93. doi:10.1016/j.neuropsychologia.2012.03.011.

170. Whittle S, Yucel M, Yap MB, Allen NB. Sex differences in the neural correlates of emotion: evidence from neuroimaging. Biol Psychol. 2011;87: 319-33. doi:10.1016/j.biopsycho.2011.05.003.

171. Domes G, Schulze L, Bottger M, Grossmann A, Hauenstein K, Wirtz PH, et al. The neural correlates of sex differences in emotional reactivity and emotion regulation. Hum Brain Mapp. 2010;31:758-69. doi:10.1002/hbm.20903.

172. Johnson DM, Shea MT, Yen S, Battle CL, Zlotnick C, Sanislow CA, et al. Gender differences in borderline personality disorder: findings from the Collaborative Longitudinal Personality Disorders Study. Compr Psychiatry. 2003:44:284-92. doi:10.1016/S0010-440X(03)00090-7.

173. Silberschmidt A, Lee S, Zanarini M, Schulz SC. Gender differences in borderline personality disorder: results from a multinational, clinical trial sample. J Pers Disord. 2015;29:828-38. doi:10.1521/pedi_2014_28_175. 
174. Banzhaf A, Ritter K, Merkl A, Schulte-Herbruggen O, Lammers CH, Roepke S. Gender differences in a clinical sample of patients with borderline personality disorder. J Pers Disord. 2012;26:368-80. doi:10.1521/pedi.2012.26.3.368.

175. Tadic A, Wagner S, Hoch J, Baskaya O, von Cube R, Skaletz C, et al. Gender differences in axis I and axis || comorbidity in patients with borderline personality disorder. Psychopathology. 2009;42:257-63. doi:10.1159/000224149.

176. Soloff P. Impulsivity, gender, and response to fenfluramine challenge in borderline personality disorder. Psychiatry Res. 2003;1 19:11-24. doi:10.1016/ s0165-1781(03)00100-8.

177. Leyton M, Okazawa H, Diksic M, Paris J, Rosa P, Mzengeza S, et al. Brain Regional alpha-[11C]methyl-L-tryptophan trapping in impulsive subjects with borderline personality disorder. Am J Psychiatry. 2001;158:775-82. doi: 10.1176/appi.ajp.158.5.775.

178. New AS, Hazlett EA, Buchsbaum MS, Goodman M, Koenigsberg HW Iskander L, et al. M-CPP PET and impulsive aggression in borderline personality disorder. Biol Psychiatry. 2003;53:104.

179. Williams LM, Korgaonkar MS, Song YC, Paton R, Eagles S, Goldstein-Piekarski $A$, et al. Amygdala reactivity to emotional faces in the prediction of general and medication-specific responses to antidepressant treatment in the randomized iSPOT-D trial. Neuropsychopharmacology. 2015;40:2398-408. doi:10.1038/npp.2015.89.

180. Windischberger C, Lanzenberger R, Holik A, Spindelegger C, Stein P, Moser U, et al. Area-specific modulation of neural activation comparing escitalopram and citalopram revealed by pharmaco-fMRl: a randomized cross-over study. Neuroimage. 2010;49:1161-70. doi:10.1016/..neuroimage.2009.10.013.

181. Paulus MP, Feinstein JS, Castillo G, Simmons AN, Stein MB. Dose-dependent decrease of activation in bilateral amygdala and insula by lorazepam during emotion processing. Arch Gen Psychiatry. 2005;62:282-8. doi:10.1001/ archpsyc.62.3.282.

182. Harmer CJ, Shelley NC, Cowen PJ, Goodwin GM. Increased positive versus negative affective perception and memory in healthy volunteers following selective serotonin and norepinephrine reuptake inhibition. Am J Psychiatry. 2004;161:1256-63. doi:10.1176/appi.ajp.161.7.1256.

183. Stahl C, Voss A, Schmitz F, Nuszbaum M, Tuscher O, Lieb K, et al. Behavioral components of impulsivity. J Exp Psychol Gen. 2014;143:850-86. doi:10.1037/ a0033981.

184. Shafer AT, Matveychuk D, Penney T, O'Hare AJ, Stokes J, Dolcos F. Processing of emotional distraction is both automatic and modulated by attention: evidence from an event-related fMRI investigation. J Cogn Neurosci. 2012;24:1233-52. doi:10.1162/jocn_a_00206.

185. Jasinska AJ, Yasuda M, Rhodes RE, Wang C, Polk TA. Task difficulty modulates the impact of emotional stimuli on neural response in cognitivecontrol regions. Front Psychol. 2012;3:345. doi:10.3389/fpsyg.2012.00345.

186. Hart SJ, Lucena N, Cleary KM, Belger A, Donkers FC. Modulation of early and late event-related potentials by emotion. Front Integr Neurosci. 2012;6:102. doi:10.3389/fnint.2012.00102.

187. Erthal FS, de Oliveira L, Mocaiber I, Pereira MG, Machado-Pinheiro W, Volchan E, et al. Load-dependent modulation of affective picture processing. Cogn Affect Behav Neurosci. 2005;5:388-95. doi:10.3758/CABN.5.4.388

188. Junhong $H$, Renlai Z, Senqi H. Effects on automatic attention due to exposure to pictures of emotional faces while performing Chinese word judgment tasks. PLoS One. 2013;8:e75386. doi:10.1371/journal.pone.0075386.

189. Lim SL, Padmala S, Pessoa L. Affective learning modulates spatial competition during low-load attentional conditions. Neuropsychologia. 2008:46:1267-78. doi:10.1016/j.neuropsychologia.2007.12.003.

190. Kanske P, Kotz SA. Concreteness in emotional words: ERP evidence from a hemifield study. Brain Res. 2007;1148:138-48. doi:10.1016/j.brainres.2007.02.044.

191. Daros AR, Zakzanis KK, Ruocco AC. Facial emotion recognition in borderline personality disorder. Psychol Med. 2013;43:1953-63. doi:10.1017/ s0033291712002607.

192. Weinberg A, Hajcak G. Beyond good and evil: the time-course of neural activity elicited by specific picture content. Emotion. 2010;10:767-82. doi:10. 1037/a0020242.

193. Schimmack U, Derryberry D. Attentional interference effects of emotional pictures: threat, negativity, or arousal? Emotion. 2005;5:55-66. doi:10.1037/ 1528-3542.5.1.55

194. Sussman TJ, Heller W, Miller GA, Mohanty A. Emotional distractors can enhance attention. Psychol Sci. 2013;24:2322-8. doi:10.1177/0956797613492774.

195. Winter D, Elzinga B, Schmahl C. Emotions and memory in borderline personality disorder. Psychopathology. 2014:47:71-85. doi:10.1159/ 000356360 .

\section{Submit your next manuscript to BioMed Central and we will help you at every step:}

- We accept pre-submission inquiries

- Our selector tool helps you to find the most relevant journal

- We provide round the clock customer support

- Convenient online submission

- Thorough peer review

- Inclusion in PubMed and all major indexing services

- Maximum visibility for your research

Submit your manuscript at www.biomedcentral.com/submit

) Biomed Central 